\title{
Efficacy of Fluoride Varnish and Cheese on White Spot Lesions Remineralization: Evaluation Using Laser Fluorescence
}

\author{
Susi Sukmasari \\ Kulliyyah of Dentistry, International Islamic University \\ Pahang, Malaysia \\ sukmasari67@gmail.com
}

\author{
Zati Balqis binti Mohammed Azme \\ Dental Officer, \\ Ministry of Health \\ Malaysia
}

\author{
Wan Nurfazliyana binti Wan Fauzi \\ Dental Officer, \\ Ministry of Health \\ Malaysia \\ Anisa Kusumawardani \\ Kulliyyah of Dentistry, International Islamic University \\ Pahang, Malaysia
}

\author{
Iswan Zuraidi Zainol \\ Kulliyyah of Dentistry, International Islamic University \\ Pahang, Malaysia
}

\begin{abstract}
Objective is to investigate the effectiveness of combining application of fluoride varnish with chewing cheese on white spot lesion remineralization. The research is a blinded quasi experimental study that was conducted on 521 occlusal white spot lesions (OWSL) of 69 dental students who were randomly assigned into three different treatment groups: Fluoride varnish (FV), Cheese (C) and combination of Fluoride varnish and Cheese (FVC). The reduction of Diagnodent reading (DR) values represented OWSL remineralization. The DR at screening was compared against DR at $2^{\text {nd }}, 4^{\text {th }}$ and $6^{\text {th }}$ weeks of followup. Paired sample t-test and ANOVA test were used for data analysis. The research is a blinded quasi experimental study that was conducted on 521 occlusal white spot lesions (OWSL) of 69 dental students who were randomly assigned into three different treatment groups: Fluoride varnish (FV), Cheese (C) and combination of Fluoride varnish and Cheese (FVC). The reduction of Diagnodent reading (DR) values represented OWSL remineralization. The DR at screening was compared against DR at 2nd, 4th and 6th weeks of follow-up. Paired sample t-test and ANOVA test were used for data analysis. The mean $( \pm S D)$ DR of $F V$ at $2^{\text {nd }}, 4^{\text {th }}$ and $6^{\text {th }}$ weeks followup were $13( \pm 5.4), 10( \pm 7.53), 10( \pm 7.23)$ and $9( \pm 6.23)$; those of $C$ were $13( \pm 5.15), 11( \pm 7.46), 11( \pm 6.96)$ and 10 $( \pm 7.04)$; and those of $\mathrm{FVC}$ were $14( \pm 5.56), 13( \pm 9.81), 12$ $( \pm 8.57)$ and $11( \pm 7.31)$ respectively. There was a significant reduction of DR within each group $(p=0.00)$. Among the 3 groups compared, DR was significantly reduced $(p=0.021)$ at $2^{\text {nd }}$ week between FV and FVC. However, there was no significant difference in DR between FV and $C(p=0.781)$ or between $\mathrm{C}$ and FVC ( $p=0.115)$. No significant difference $(p>0.05)$ in DR at screening, and at the $4^{\text {th }}$ and $6^{\text {th }}$ weeks was observed among all 3 groups. All 3 treatments had remineralization effect on white spot lesions with significant results at $2^{\text {nd }}$ week. However, the most effective treatment could not be determined
\end{abstract}

Keywords-white-spot, fluoride, cheese, Diagnodent reading

\section{INTRODUCTION}

Oral health is crucial for wellbeing and is a determinant in quality of life. In fact, oral health is considered an integral part of general health. The possible associations between oral health especially dental caries and systemic diseases such as cardiovascular diseases, diabetes mellitus, and even certain types of cancers, are described in literature (Hujoel, 2009). The Malaysian Oral Health Survey on 6-year old children carried out in 2007 showed that caries prevalence had decrease till $75.5 \%$, but caries severity increased (National Oral Health Plan for Malaysia: 2011-2020). Based on this survey, it is apparent that the prevalence of dental caries in Malaysia is an increasing trend which needs tremendous attention in order to improve the oral healthcare in Malaysia.

Dental caries is a chronic disease, a process that progresses slowly in most individuals and affects the enamel, dentin and cementum (Kidd and Fejerskov, 2004). Modern evidence reveals that there is a continuum of disease states ranging from subclinical and subsurface changes to more advanced, clinically detectable subsurface caries (with so-called "intact" surface layers), to various stages of more advanced lesions with microscopic and later macroscopic cavitation of enamel and significant involvement of dentin (Featherstone, 2004; Kidd, 2004). Therefore, dental caries is more than just a "cavity", it is a disease process with the first clinical manifestation as a white opaque lesion or spot. It is an early initial caries before the tooth becomes cavitated. White spot lesions are formed due to an imbalance between de-mineralization and 
remineralization on the tooth surface, optically visible evidence of enamel caries and is due to an optical phenomenon which is caused by mineral loss in the subsurface enamel (Featherstone, 1999, Gorelick et al., 1982). Histologically, a well-mineralized surface layer covers a demineralized subsurface zone, (Alexander and Ripa, 2000).

There are several consequences pertaining to this condition that can affect an individual's daily life. For instance, the cavity may emit an unpleasant odor and cause bad breath (halitosis) (Bollen and Beikler, 2012). This directly affects the normal social life of the person. The tooth decay may also lead to persistent pain, which affects one's appetite, studies, work, sleep or even general health. When there is severe tooth decay, the bacteria may spread from the pulp to the surrounding periodontal tissues through the apex of the tooth which later leads to inflammation or even formation of dental abscesses (Dahlen and Moller, 1991). As the saying goes, prevention is better than cure. Thus, before the white spot lesions progress into a cavitated lesion and disturb one's daily life (Hiremath, 2007), it is important to prevent the progression of the disease and revert initial signs of demineralization.

Preventive strategies have been developed and tested to address all major aspects of the etiology of caries. White spot lesion prevention can be achieved by applying a combination of both professional dental care and home-based patient oral care. Topical fluorides (mouthrinses, gels, or varnishes) used in addition to fluoride toothpaste achieve a modest reduction in caries compared to toothpaste use alone (Marinho et al., 2004). This study will focus on the application of fluoride varnish as dental professional care treatment and the consumption of cheese as home-based oral care. Fluoride gels and varnishes are typical methods of professional topical fluoride application and both delivery systems have been used in preventive programs (Marinho et al., 2004). Cheese has be pronounced as an anticaries effect as it appears to enhance remineralization in addition to reducing demineralization (Kashket and Shelby, 2002).The aim of modern dentistry must be a preventive approach rather than invasive repair of the disease. This is only possible with early detection and respective preventive measures. Therefore, a sensitive diagnostic tool is laser fluorescence (Diagno-dent), it is important to detect an early onset of tooth demineralization. Individuals have at their disposal many methods that they can use to prevent dental caries. Behaviors such as dental visits, use of fluoride products, antimicrobial agents, good oral hygiene and dietary practice can affect caries incidence throughout life. Methods that rely on individual behaviors are not included in this study.

The aim of this study is to assess the efficacy of a combination of fluoride varnish and cheese on white spot lesion remineralization, evaluated using laser fluorescence. The specific objectives are to determine Diagno-dent readings of remineralized white spot lesions treated with fluoride varnish, with cheese and with a combination of fluoride varnish and cheese.

\section{MATERIALS AND METHODS}

A total of 72 students agreed to participate voluntarily in this study. However, 3 students withdrew from this study and the total number was 69 students. A researcher blinded quasi experimental study was conducted on 521 occlusal white spot lesions (OWSL) from 69 dental student dentitions who were randomly assigned into three different treatment groups. OWSL in each group were treated with either Fluoride varnish (FV), Cheese (C) or a combination of Fluoride varnish and Cheese (FVC). The reduction of Diagno-dent reading (DR) values represented remineralization on OWSL. The DR at screening was compared against DR at 2nd, 4th and 6th weeks follow-up. Paired sample ttest and ANOVA test were used for data analysis.

The students in this study were included based on the following criteria: (i) medically fit students, (ii) students with white spot lesions, and (iii) students with normal salivary test. The exclusion criteria were: (i) students with systemic illness and (ii) students with allergy to milk and its derivatives.

The students were screened by two researchers based on the International Caries Detection Assessment System (ICDAS), codes 1 and 2. (i) D1 = Opacity or discoloration hardly visible on a wet surface, but distinctly visible after air drying. Enamel demineralization limited to the outer $50 \%$ of the enamel layer. (ii) $\mathrm{D} 2=$ Opacity or discoloration distinctly visible without air drying. No clinical cavitation detectable. Demineralization involving between $50 \%$ of the enamel and the outer third of dentin was visible.

The reading values were taken using a laser fluorescence device, Diagno-dent that indicates the progression of white spot lesions. Three caries progression levels were assigned based on Diagno-dent readings: (i) 0-4: no caries, or histological enamel caries limited to the outer half of the enamel thickness, (ii) 15 20: histological caries extending beyond the outer half, but confined to the enamel, (iii) 21-99: histological dentinal caries. Treatment recommendations were as follow: (i) $0-14$ : no active care is advised, (ii) $15-20$ : preventive care is advised, (iii) 21 - 30: preventive or operative care is advised depending on the patient's caries risk, the recall interval etc., (iv) $>30$ : operative and preventive care is advised.

After screening, the students were given Oral Hygiene Education (OHE) and Oral Hygiene Instruction (OHI). Scaling also was done to remove all of the calculus and plaque. Fluoride varnish 5\% NaF $(22,600 \mathrm{ppm}$ fluoride) was applied on the OWSL only once during this study for the group treated with Fluoride varnish (FV) and group treated with combination of Fluoride varnish and Cheese (FVC). For the groups treated with Cheese (C) and with a combination of Fluoride varnish and Cheese (FVC), the students were given a $2 \mathrm{~cm} \times 2 \mathrm{~cm}$ slice of cheese 
(cheddar) each. A guideline was given to all students to be followed according to their treatment groups.

Two weeks after screening, all the participants were examined in the first follow-up examination. The time interval between follow-up was two weeks. Reading values using the laser fluorescence device, Diagno-dent was recorded during each follow-up. The data was collected and recorded by two researchers. The reading values using Diagno-dent were taken three times.

Significant differences in the three different treatment groups were assessed by mean and paired sample t-test with 95\% CI and ANOVA. All statistical analyses were conducted using SPSS version 16.0. Differences were considered significant at $\mathrm{p}<0.05$.

\section{RESULTS}

A total of 69 volunteered dental students including 59 females and 10 males participated in this study. The participants' age were between 21 and 23 years old. All participants were Malay during the research and lived in a hostel. They had the same schedules for breakfast and lunch. The participants also used fluoridated toothpaste daily.

TABLE I. DEMOGRAPHIC DATA

TABLE I. DEMOGRAPHIC DATA
\begin{tabular}{|l|l|l|c|}
\hline \multicolumn{1}{|c|}{ Gender } & Frequency & \multicolumn{1}{c|}{ Race } & Age \\
\hline Male & 10 & Malay & $21-23$ \\
\hline Female & 59 & Malay & $21-23$ \\
\hline
\end{tabular}

The teeth most affected by OWSL were the right and left mandibular permanent first molars followed by the right and left maxillary permanent first molars, with numbers $69,69,61$ and 50 respectively.

TABLE II. DISTRIBUTION OF TEETH AFFECTED BY

\begin{tabular}{|c|c|c|c|c|}
\multicolumn{5}{|c|}{ OCCLUSAL WHITE SPOT LESIONS } \\
\cline { 2 - 5 } Tooth & \multicolumn{5}{|c|}{ Treatment Group } \\
\hline 14 & 6 & 5 & 13 & 24 \\
\hline 15 & 5 & 8 & 4 & 17 \\
\hline 16 & 21 & 23 & 17 & $\mathbf{6 1}$ \\
\hline 22 & 0 & 1 & 0 & 1 \\
\hline 24 & 4 & 6 & 11 & 21 \\
\hline 25 & 5 & 13 & 5 & 23 \\
\hline 26 & 14 & 20 & 16 & $\mathbf{5 0}$ \\
\hline 33 & 0 & 1 & 0 & 1 \\
\hline 34 & 13 & 11 & 15 & 39 \\
\hline 35 & 16 & 15 & 16 & 47 \\
\hline 36 & 24 & 22 & 23 & $\mathbf{6 9}$ \\
\hline 44 & 16 & 15 & 14 & 45 \\
\hline 45 & 21 & 15 & 14 & 50 \\
\hline 46 & 26 & 27 & 16 & $\mathbf{6 9}$ \\
\hline 47 & 4 & 0 & 0 & 4 \\
\hline Total & 175 & 182 & 164 & 521 \\
\hline & & & & \\
\hline
\end{tabular}

In children with SECC, most of the salivary $\mathrm{pH}$ was very acidic (17 children, 56.7\%) and acidic (12 children, 40\%) and only 1 children had normal salivary $\mathrm{pH}$, whereas in caries-free children, most of the salivary $\mathrm{pH}$ was normal (26 children, $86.7 \%$ ), only a few had acidic salivary $\mathrm{pH}$ (4 children, $13.3 \%$ ), and there were no children with very acidic salivary $\mathrm{pH}$. Based on the statistical test, there were difference in salivary $\mathrm{pH}$ between SECC and caries-free children $(\mathrm{p}<0.001)$ (Table III).

TABLE III. DISTRIBUTION OF DIAGNO-DENT READING DURING SCREENING

\begin{tabular}{|c|c|c|}
\hline Values & Frequency & Percent (\%) \\
\hline 5 & 1 & 0.2 \\
\hline 6 & 2 & 0.4 \\
\hline 7 & 11 & 2.1 \\
\hline 8 & 43 & 8.3 \\
\hline 9 & 60 & 11.5 \\
\hline 10 & 75 & 14.4 \\
\hline 11 & 51 & 9.8 \\
\hline 12 & 41 & 7.9 \\
\hline 13 & 39 & 7.5 \\
\hline 14 & 23 & 4.4 \\
\hline 15 & 27 & 5.2 \\
\hline 16 & 23 & 4.4 \\
\hline 17 & 19 & 3.6 \\
\hline 18 & 19 & 3.6 \\
\hline 19 & 16 & 3.1 \\
\hline 20 & 13 & 2.5 \\
\hline 21 & 1 & 0.2 \\
\hline 22 & 6 & 1.2 \\
\hline 23 & 8 & 1.5 \\
\hline 24 & 12 & 2.3 \\
\hline 25 & 7 & 1.3 \\
\hline 27 & 9 & 1.7 \\
\hline 28 & 4 & 0.8 \\
\hline 29 & 7 & 1.3 \\
\hline 30 & 4 & 0.8 \\
\hline Total & 521 & 100.0 \\
\hline & & \\
\hline & & \\
\hline
\end{tabular}

Reduction in Diagno-dent reading value was observed in all treatment groups. The means $( \pm \mathrm{SD})$ of the FV treatment group were $13( \pm 5.4), 10( \pm 7.53), 11$ $( \pm 7.23)$ and $10( \pm 6.23)$; those of $C$ treatment group were $13( \pm 5.15), 11( \pm 7.46), 11( \pm 6.96)$ and $10( \pm 7.04)$; and those of FVC treatment group were $14( \pm 5.56), 14$ $( \pm 9.81), 12( \pm 8.57)$ and $11( \pm 7.31)$ respectively, as shown (Table IV).

TABLE IV. OVERVIEW OF REDUCTION IN DIAGNO-DENT READING

\begin{tabular}{|c|c|c|c|c|c|c|}
\hline & \multicolumn{2}{|c|}{$\begin{array}{l}\text { Fluoride } \\
\text { Varnish } \\
(\mathrm{N}=182)\end{array}$} & \multicolumn{2}{|c|}{$\begin{array}{c}\text { Cheese } \\
(\mathrm{N}=175)\end{array}$} & \multicolumn{2}{|c|}{$\begin{array}{c}\text { Fluoride } \\
\text { Varnish and } \\
\text { Cheese } \\
(\mathbf{n}=\mathbf{1 6 4})\end{array}$} \\
\hline & Mean & SD & Mean & SD & Mean & SD \\
\hline Screening & 13.14 & 5.470 & 13.35 & 5.153 & 14.35 & 5.561 \\
\hline $\begin{array}{l}\text { Follow-up } \\
\left(2^{\text {nd }} \text { week }\right)\end{array}$ & 10.35 & 7.526 & 11.09 & 7.461 & 13.87 & 9.812 \\
\hline $\begin{array}{l}\text { Follow-up } \\
\left(4^{\text {th }} \text { week }\right)\end{array}$ & 10.77 & 7.225 & 11.01 & 6.964 & 12.09 & 8.572 \\
\hline $\begin{array}{l}\text { Follow-up } \\
\left(6^{\text {th }} \text { week }\right)\end{array}$ & 9.74 & 6.233 & 10.45 & 7.035 & 10.90 & 7.313 \\
\hline
\end{tabular}


TABLE V. COMPARISION OF DIAGNO-DENT READING AT $2^{\mathrm{ND}}, 4^{\mathrm{TH}}$ AND $6^{\mathrm{TH}}$ WEEKS FOLLOW-UP AGAINST SCREENING VALUES

\begin{tabular}{|l|c|c|}
\hline & df & $\begin{array}{c}P \text { - } \\
\text { value }\end{array}$ \\
\hline Screening & 2 & 0.90 \\
\hline $\begin{array}{l}\text { Difference between Diagno-dent reading after 2 } \\
\text { weeks follow-up against screening Diagno-dent } \\
\text { reading }\end{array}$ & 2 & 0.00 \\
\hline $\begin{array}{l}\text { Difference between Diagno-dent reading after 4 } \\
\text { weeks follow up against screening Diagno-dent } \\
\text { reading }\end{array}$ & 2 & 0.234 \\
\hline $\begin{array}{l}\text { Difference between Diagno-dent reading after 6 } \\
\text { weeks follow up against screening Diagno-dent } \\
\text { reading }\end{array}$ & 2 & 0.283 \\
\hline
\end{tabular}

Table VI shows that no significant differences ( $p>0.05$ ) were present between Diagno-dent readings in the 2nd, 4th, and 6th weeks between 3 groups.

TABLE VI. SIGNIFICANT DIFFERENCES BETWEEN GROUPS

Differences between screening and follow-up Diagno-dent

\begin{tabular}{|c|c|c|c|c|c|c|c|c|}
\multicolumn{8}{|c|}{ readings $^{\text {th }}$ week } & \multicolumn{3}{c|}{$\mathbf{6}^{\text {th }}$ week } \\
\hline \multicolumn{3}{|c|}{$\mathbf{2}^{\text {nd }}$ week } & \multicolumn{1}{c|}{$\mathbf{4}^{\text {th }}$ weer } & CoC & CV & CoV & CoC \\
\hline CV & CoV & CoC & CV & CoV & Co \\
0.78 & $\mathbf{0 . 0 2 1}$ & 0.115 & 0.993 & 0.974 & 0.994 & 0.751 & 0.766 & $\mathbf{1 . 0 0 0}$ \\
\hline
\end{tabular}

\section{DISCUSSION}

Dental caries is a multifactorial disease (LenanderLuminari and Loimaranta, 2000; Carlos et al, 2010). It can be influenced by microorganisms, diet, teeth, time and demographic factors such as age, gender, race and socioeconomic status (Carlos et al, 2010). This study involved 69 Malay dental students with aged between 21 and 23 years old, selected among dental students while considering that they shared the similar workplace, daily work schedule and meal time including breakfast and lunch. Thus, it was easy to monitor and control cheese distribution as well as application of fluoride varnish to the participants. In terms of equal number of participants between males and females, it was difficult to apply in this study as there were fewer male dental students compared to female dental students.

Under normal circumstances, the buffering action of saliva counteracts $\mathrm{pH}$ reduction to prevent dental caries from developing. However, long-term repeated fall in $\mathrm{pH}$ causes de-mineralization of susceptible tooth surfaces and caries develops. The frequency at which teeth are exposed to cariogenic i.e. acidic environments also affects the likelihood of caries development. Application of fluoride varnish hopefully can be strengthen the enamel structure to acid attack, then application of cheese as a snack or chewing habits can be improve the alkaline environment of the saliva between meal time.

There are two subdivisions of enamel demineralization. The first, surface softening, is the initial preferential removal of interprismatic minerals at the enamel surface, which occurs at $\mathrm{pH} 2-4$ over a short period of time. The second is subsurface lesion formation. The area of dissolution occurs mainly in the deeper part of the enamel where a mineral-rich intact layer covers a porous layer. The $\mathrm{pH}$ of this phenomenon involves a range of 4.5-6.5 over a longer period of time (Arends, 1981) whilst the surface zone is free of cavitation and continuously undergoes re-mineralization or demineralization. This zone has an appearance similar to sound enamel (Darling, 1961). This condition is due to the reposition of minerals such as calcium, phosphate and fluoride after its initial loss (Robinson, 2000). Diagnodent can read the broken minerals on the white spot without breaking the weak surface enamel. White spot lesions can be completely reversible (Reynolds, 2010), then detection of white spot using visual and sensitive tools can be enhanced that the patient strongly need the prevention action as soon as possible.

A specific laser fluorescence measuring tool, Diagno-dent is used in this study to assess occurrence of the remineralization process. Previous studies have mentioned that the diagnostic performance of Diagnodent method is superior to that of radiography (Shi, Welander, Angmar-Mansson, 2000). Treatment recommendations for Diagno-dent readings are: (i) 0 14: no active care is advised, (ii) 15 - 20: preventive care is advised, (iii) 21 - 30: preventive or operative care is advised depending on the patient's caries risk, the recall interval etc., and (iv) $>30$ : operative and preventive care is advised. In this study, the Diagnodent readings for all OWSL were below or equal to 30 .

In terms of dental professional care, several methods of prevention are available such as providing oral health instructions and oral health education, application of topical fluoride whether in gel or varnish form, using fissure sealants, preventive resin restoration and oral prophylaxis. Fluoride varnish is very effective in preventing caries in both primary and permanent dentition, especially in high-risk patients. It has been proven that topical fluoride, especially fluoride varnish provides good results in enhancing white spot lesion remineralization. Several studies have shown that fluoride varnish is the gold standard for prevention of caries. In this study, the results were in accordance with this statement, and were in line with previous studies stating the remineralization potential of fluoride varnish on white spot lesions. It's showed that fluoride varnish reduced Diagno-dent reading values, indicating white spot lesion remineralization (See table 4 and figure 1). The distribution table above shows that treatment with fluoride varnish led to higher reduction in Diagno-dent reading values com-pared to the cheese and combination treatment groups.

Previous study showed that processed cheese is anticariogenic, increasing of plaque $\mathrm{pH}$ in humans during cheese consumption, does not decrease $\mathrm{pH}$, and found that chewing cheddar cheese after consumption of a sugary food rapidly returned plaque $\mathrm{pH}$ towards neutrality. Furthermore, they found that the cheese by itself stimulated salivary flow, that the $\mathrm{pH}$ of the saliva rose to approximately 7.5 after 2 minutes of flow, and that plaque calcium levels increased after cheese chewing. Most recently, Moynihan et al. (1999) 
reported that cheese-containing meals increased plaque calcium concentrations to a significantly greater level than control meals lacking cheese. Indeed, findings that cheese and milk casein phosphopeptides appeared to enhance remineralization, in addition to reducing demineralization, lends further credence to the general conclusion that cheese has a pronounced anti-caries effect (Kashket et al., 2002). Consuming cheese reduces the effect of metabolic acids and helps restore enamel that is lost during eating (Kashket et al., 2002).The mechanism of caries prevention using-cheese involves buffering, salivary stimulation, reduction of bacterial adhesion, reduction of enamel demineralization, and/or promotion of remineralization by casein replacement of $\mathrm{Ca}$ and P. Cheese-containing meals increase plaque calcium concentration and thus protect against dental caries (Moynihan et al., 1999). Several investigators have since confirmed that milk, cheese, caseins and whey proteins reduce caries development even in highly susceptible rats, such as desalivated rats. These results are supported by a large number of in situ studies. The results of the present study indicate that cheese had remineralization effects on OWLS, similar to results from a previous study stating that cheese had the highest anti-cariogenic effect among all the dairy products studied. The results of the present study are comparable to previous studies indicating that cheese had the highest anti-cariogenic activity among the dairy products tested.

As mentioned before, dental caries is a multifactorial disease. Thus, the prevention of dental caries should involve multiple treatments. Some studies on the efficacy of combination treatments for caries prevention have been carried out; for instance, study on the efficacy of treatments using fluoride varnish and sorbitol, CPP-ACP, and antimicrobials. In the present study, a combination of professional and home-based oral care was provided via the application of fluoride varnish and chewing of cheese.

Although the action of fluoride in remineralization is the gold standard against which other remineralization systems are compared, ideal remineralization methods should diffuse or deliver calcium and phosphate into the (sub) surface lesions or boost the remineralization properties of saliva and oral reservoirs. Nowadays, many people are busy and may not have time to brush their teeth after every meal. Based on previous studies pointing towards the efficacy of chewing cheese during and after meals in the remineralization of white spot lesions, we aimed to assess the efficacy of three different treatments for dental caries prevention. The treatments are: application of fluoride varnish, chewing cheese and a combination of both fluoride varnish and cheese treatments.

The results of this study showed that Diagno-dent reading values were reduced when OWSL was treated with chewing cheese alone, applying fluoride varnish alone and applying a combination of chewing cheese and fluoride varnish. However, the decrease in Diagnodent readings was small across all groups. Nevertheless, in the 2nd week follow-up, treatments combining the application of fluoride varnish and chewing cheese and using fluoride varnish alone had slightly greater remineralization effects compared to chewing cheese alone.

However, the difference in efficacy between treatment groups could not be deter-mined. This was due to the small sample size as well as limited followup time. Confounding factors such as the participants' habits should be more restricted. To obtain more valid results, the recommended design for further study would be a randomized controlled trial with cross-over data collection. Results from this study indicate that practicing chewing cheese after eating without neglecting professional and home-based topical fluoride application can be an effective method for dental caries prevention.

As a conclusion, all 3 treatments had remineralization effect on white spot lesions with significant results after the 2nd week; however, the most effective group could not be determined.

\section{ACKNOWLEDGMENT}

The publication of this study under grant 2016: RIGS16-325-0489. We are grateful to all the 1st year and 2nd year students of IIUM Kulliyyah of Dentistry 2013/2014 for their participation and cooperation in this study.

\section{REFERENCES}

[1] American Dental Association Council on Scientific Affairs, "Professionally applied topical fluoride: evidence-based clinical recommendations," J. Am. Dent. Assoc., vol. 137(8), pp. 11511159, 2006.

[2] O.B. Dirks, "Posteruptive changes in dental enamel," Journal of Dental Research, vol. 45, pp. 503-511, 1966.

[3] R. Carlos, et al., "Effect of caries infiltration technique and fluoride therapy on the colour masking of white spot lesions," Av. Eng. Francisco Jose' Longo, 777, Jd. Sa o Dimas, Sa o Jose' dos Campos, SP, CEP:12245-000, Brazil. 2010.

[4] International Journal of Dentistry Volume 2010, Article ID 649643, 5 pages J Conserv Dent. 2009 Jan-Mar; 12(1): 1

[5] M.E. Jensen, J.S. Wefel, "Effects of processed cheese on human plaque $\mathrm{pH}$ and demineralization and remineralization," Am. J. Dent., vol. 3, pp. 217-223, 1990.

[6] S. Kashket, DePaola, P. Dominick, "Cheese consumption and the development and progression of dental caries," Nutrition Reviews, vol. 60(4), pp. 97-103, April 2002

[7] M. Lenander-Lumikari, V. Loimaranta," Saliva and dental caries,” Adv. Dent. Res., vol. 14, pp. 40-47, December 2000.

[8] P.J Moynihan, S. Ferrier, G.N Jenkins, "The cariostatic potential of cheese: cooked cheese-containing meals increase plaque calcium concentration," British Dental Journal, vol. 187, pp. 664-667, December 1999.

[9] P.E. Petersen, "The world oral health report 2003: Continuous improvement of oral health in the 21 st century--the approach of the who global oral health programme," Community Dent. Oral Epidemiol., vol. 31(Suppl 1), pp. 3-23, 2003.

[10] E.C.N.B. Reynolds, Anticariogenic: phosphopeptides, 5015628, 1991.

[11] L.M. Silverstone, "Remineralization phenomena," Caries Res. vol. 11(Suppl 1), pp. 59-84, 1977.

[12] S.S. Hiremath, Textbook of preventive and community dentistry.

[13] J.W. Valk, C.L. Davidson, "The relevance of controlled fluoride release with bonded orthodontic appliances," J. Dent., vol. 15, pp. 257-260, 1987. 
[14] K. Srivastava, T. Tikku, R. Khanna, K. Sachan, "Risk factors and management of white spot lesions in orthodontics," J. Orthodont. Sci., vol. 2, pp. 43-49, 2013.

[15] E. Reynolds, AO, PCSO Bulletin Northern Region Editor. The PCSO Annual Session, October 2010.

[16] V.C.C. Marinho, J.P.T. Higgins, A. Sheiham, S. Logan, "Combinations of topical fluoride (toothpastes, mouthrinses, gels, varnishes) versus single topical fluoride for preventingdental caries in children and adolescents (Review)," The Cochrane Library, Issue 1, 2009. 